\title{
Monitoring of Mycotoxins in Feed for Dairy Cows and Swine from Muntenia Region, Romania
}

\author{
Aneta MARINA ${ }^{1}$, Marian MIHAIU ${ }^{1}$, Liora Mihaela COLOBĂŢIU ${ }^{2}$, Romolica MIHAIU ${ }^{3}$, Rodica Cristina \\ SOBOLU $^{4}$, Ana-Andreea CIOCA ${ }^{1 *}$ \\ ${ }^{1}$ Department of Animal Husbandry and Food Safety, University of Agricultural Sciences and Veterinary \\ Medicine, Faculty of Veterinary Medicine, 3-5 Mănăștur Street, Cluj Napoca, Romania \\ ${ }^{2}$ Department of Medical Devices, Iuliu Hațieganu University of Medicine and Pharmacy, 8 Babeș Street, \\ 400012, Cluj-Napoca, Romania \\ ${ }^{3}$ Department of Management, Babeş-Bolyai University, Faculty of Economics and Business Administration, \\ Management Department, 58-60 Teodor Mihali Street, 400591, Cluj-Napoca, Romania \\ ${ }^{4}$ Department of Terrestrial Measurements and Exact Sciences, University of Agricultural Sciences and \\ Veterinary Medicine, 3-5 Mănăştur Street, 400372, Cluj-Napoca, Romania. \\ *corresponding author: anaandreeacioca@yahoo.com
}

Bulletin UASVM Veterinary Medicine 76(2)/2019

Print ISSN 1843-5270; Electronic ISSN 1843-5378

doi:10.15835/buasvmcn-vm:2019.0026

\begin{abstract}
Mycotoxins have a strong negative impact on crops, animal health and human health. These secondary metabolites are toxic can cause major economic losses and illnesses (Zain, 2011). This study aimed to evaluate the presence of the most prevalent mycotoxins, aflatoxin B1 (AFB1), ochratoxin A (OTA), deoxynivalenol (DON) and zearalenone (ZEN), in feed intended for dairy cows and swine from farms located in the Region of Muntenia (Călăraşi, Giurgiu and Teleorman), Romania. 136 samples of fodder and forage intended for cattle and 37 samples for pigs were collected during 2017 - 2018. Some of the samples were analyzed within the national surveillance program and some on request. AFB1 has been extracted and purified in an immunoaffinity column specific for AFB1. Detection and quantification of toxic secondary metabolites were performed by high-performance liquid chromatography (HPLC) and Enzyme-Linked ImmunoSorbent Assay (ELISA). All four mycotoxins were detectable and quantifiable. The level of contamination was generally low. The maximum allowable limits for AFB1, OTA, DON and ZEN were not exceeded. The low level of contamination indicates no potential risks for animal and human health and suggests that the best practices in the management and storage of feed were applied in the studied area.
\end{abstract}

Keywords: dairy cows, feed, mycotoxins, monitoring, swine

\section{Introduction}

Mycotoxins are secondary metabolites of certain molds (fungi) that can adversely affect animal and human health because of their toxicity (Alshannaq and Yu, 2017; Fink-Gremmels and Van der Merwe, 2019). Their negative effects can be observed in all vertebrates, but a special interest has been given the species of animals that can provide food products for humans (cattle swine, sheep, goats, poultry, etc). Multiple studies conducted in the las decade involve the detection and quantification of mycotoxins not only in animal origin products (Becker-Algeri et al., 2016), but also in plant origin products (Barkai-Golan and Paster, 2008). From the last group, animal feed is apparently more prone to contamination with mycotoxins (Gruber-Dorninger et al., 2018, Tola and Kebede, 2016). Feedstuffs for cattle and swine were analyzed worldwide in the last 5 years (Changwa et al., 2018; Li et al., 2014, Ma et al., 2018). Monitoring primary production can prevent the contamination of future products and also of the food 
chain, in general (Fink-Gremmels and Van der Merwe, 2019; Pinotti et al., 2016; Schatzmayr and Streit, 2013). The importance of this step is linked to the economic losses that contaminated products can produce. Beside the economic losses that mycotoxins can cause, such as health problems or even death in humans, their occurrence implies significant economic losses also in areas like crop growth, animal production, food processing (animal or vegetable origin), veterinary care, national and international trades, research on the topic, etc (Bryden, 2012; Hussein and Brasel, 2001; Iheshiulor et al., 2010, Zain, 2011).

Presently, over 300 mycotoxins have been identified and reported. This number includes some of the most dangerous mycotoxins: aflatoxins (AF), ochratoxins (OTA), fumonisins, patulins, zearalenones (ZEN), and trichothecenes including deoxynivalenol (DON) and T-2 toxin). These groups showed increased popularity on a global scale due to their high prevalence and toxicity (Marin et al. 2013).

AFB1 is a secondary metabolite of Aspergillus flavus and Aspergillus parasiticus. The exposure to this mycotoxin after contaminated feedstuff ingestion can lead to a very serious health issue, the hepatocellular carcinoma (HCC) (Hamid et al., 2013; Magnussen and Parsi, 2013). Moreover, when AFB1 becomes metabolized in the organism of dairy cattle, another problem arises. AFB1 is converted to AFM1 and excreted in milk. Therefore, milk and milk products can also serve as an indirect source of aflatoxins (Iqbal et al., 2015; Iqbal et al., 2016). Lately, a great number of studies have been conducted on aflatoxins as a result of the concern for food safety and human health (Kumar et al., 2017). The International Agency for Research on Cancer (IARC) described AFB1 and AFM1 as human carcinogens and placed them in Group 1 and Group 2B (IARC, 1993).

OTA is produced by several species of Aspergillus and Penicillium and it is nephrotoxic and nephrocarcinogenic (Bui-Klimke and $\mathrm{Wu}$, 2015). OTA belongs to Group 2B, possibly carcinogenic to humans, based on demonstrated carcinogenicity in animal studies (IARC, 1993).

ZEN is a nonsteroidal estrogenic mycotoxin produced by several species of Fusarium. The toxin is responsible for oestrogenic effects and several studies refer to it a endocrine disruptor (Kowalska et al., 2016; Metzler et al., 2015).
DON is the most frequent trichothecene contaminant of agricultural crops throughout the world and it is produced by species such as Fusarium graminearum, Fusarium cerealis and Fusarium culmorum. DON does not constitute a significant threat to public health, but it can affect the immune system and cause temporary nausea, vomiting, diarrhea, abdominal pain, headache, dizziness, and fever to both humans and animals (Sobrova et al., 2010).

In 2018, Romania has ranked $3^{\text {rd }}$ place in the European Union (EU) in grain harvest. Also, in the years before 2018 other records for maize were obtained. Being an important producer on the EU market, for products that can serve as either feed or food, requires careful monitoring of mycotoxins, especially in areas were the presence of AFB1, OTA, ZEN and DON were previously reported (e.g. West Romania, SE Romania, etc) (Alexa et al. 2013; Gagiu et al., 2018; Stanciu et al., 2019; Tabuc et al., 2011).

\section{Materials and methods Sample Collection}

A total of 271 feed samples were taken from 3 counties located in Romania between January 2017 and December 2018. The counties of origin and the sample numbers are represented in Figure 1. The samples collected in 2017 were represented by fodder and forage for diary cows and pigs $(\mathrm{n}=156)$. The fodder and forage material collected in 2018 was exclusively part of the feed for dairy cows $(n=115)$. Various categories of samples were taken into study. The first category, cattle feedstuff, included combined fodder, grain legumes, grain cereals (barley, maize, wheat), soy grist, rapeseed grist, maize silage, corn, alfalfa hay, middlings, pickled fodder (maize silage/ alfalfa silage), sunflower grist. The second category, swine feedstuff, was composed of combined fodder, grain legumes, grain maize, grain cereals, soy grist and rapeseed grist.

\section{Instrumental Analysis}

In the process of selecting and implementing the appropriate method the following aspects were considered: compliance with international regulatory limits, facility and accessibility in active monitorization conditions (sample number and cost-analysis ratio).

The HPLC method performed on one part of the collected samples was described by Irakli et al., 2017. The other part was analyzed using the 


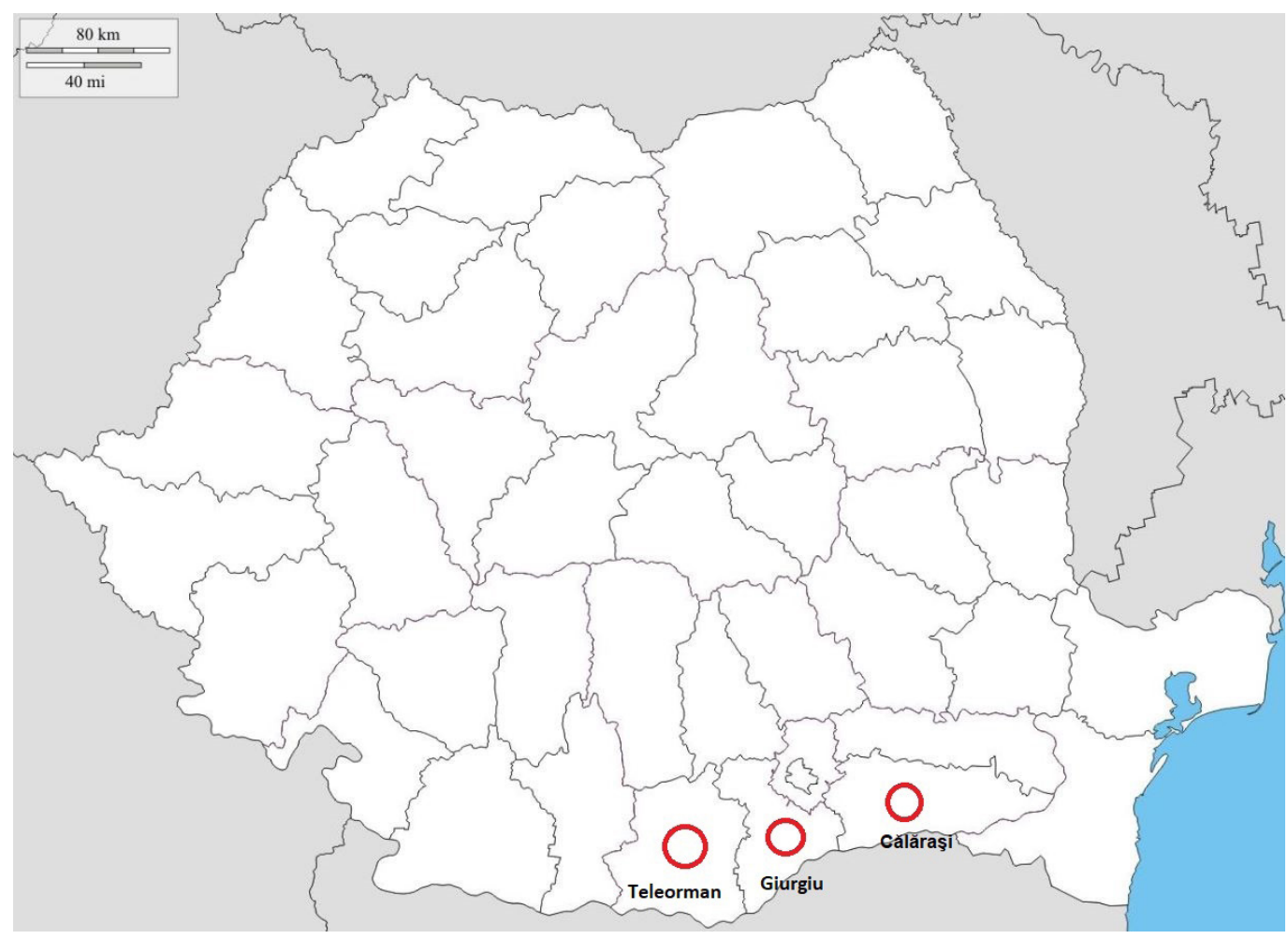

Figure 1. Studied Area during 2017-2018

ELISA method. The principle of the ELISA was described by Zheng et al., 2006. The ELISA kits for the identification of AFB1, OTA, DON and ZEN were ordered and purchased from R-Biopharm (Darmstadt, Germany) and used according to the indications of the producer.

\section{Results and discussions}

The maximum residue limits (MRLs) for AFB1, OTA, DON, ZEN in feed are regulated by EC Directive 32/2002 and EC Commission Recommendation 576/2006. The MRLs were compared to the results obtained after performing Enzyme-Linked ImmunoSorbent Assay (ELISA) and high-performance liquid chromatography (HPLC) Analyses on Feed Samples.
Table 1 reveals contamination rate with different mycotoxins in feed samples collected between 2017-2018. Aflatoxin B1 (AFB1) was the mycotoxin with the highest incidence in dairy cow. Tabuc et al., 2011 has mentioned that this toxin in particular must be continuously monitored in SE Romania. The results of ochratoxin A (OTA), deoxynivalenol (DON) and zearalenone (ZEN) were generally low and followed the trend $\mathrm{ZEN}<\mathrm{DON}<\mathrm{OTA}<\mathrm{AFB} 1$ in dairy cow feed from 2017 and 2018. It appears that in SE Romania the incidence of mycotoxins is different than in West Romania, where Alexa et al., 2013 revealed that DON has recorded an incidence of $73.08 \%$ in the samples harvested in 2010.

Table 1. Mycotoxin Contamination Rate

\begin{tabular}{lcccccc}
\hline Type of Feed & Period & AFB1 & OTA & DON & ZEN & Aflatoxin $\Sigma$ \\
\hline Bovine Feed & 2017 & $74.58 \%$ & $10.17 \%$ & $9.32 \%$ & $5.93 \%$ & - \\
\hline Bovine Feed & 2018 & $63.72 \%$ & $16.81 \%$ & $10.62 \%$ & $7.08 \%$ & $1.77 \%$ \\
\hline Swine Feed & 2017 & $45.56 \%$ & $2.7 \%$ & $21.62 \%$ & $5.41 \%$ & - \\
\hline
\end{tabular}


In this study, the incidence values of DON in dairy cow feed from 2017 were similar to the values of the same toxin, in the same samples from 2018 (Tab. 1). The incidence similarity between the years 2017 and 2018 was also observed in ZEN, although at lower levels. A slightly higher variability was observed in AFB1 and OTA in the consecutive years (marked with red circles in Figure 2).

The analysis of swine feed from 2017 showed that the most encountered mycotoxin was AFB1 with a rate of $45.56 \%$, followed by DON $(21.62 \%)$, ZEN (5.41\%) and OTA (2.7\%) (Tab. 1). The trend
AFB1 $>$ DON $>$ ZEN $>0$ OTA is in accordance with the trend described by Gagiu et al., 2018.

Table 2 presents the distribution of mycotoxins in feed by county of origin. All of the samples collected from the 3 counties, regardless of the feed type, revealed strong positive results for AFB1. The highest prevalence of AFB1 was registered in Giurgiu country in 2018 (100\% in dairy cow feed). Therefore, all different types of feed from Giurgiu were contaminated with AFB1 residues. OTA occurrence was mainly associated with Călăraşi county. In this location some of the feed samples coming from dairy cow feed revealed

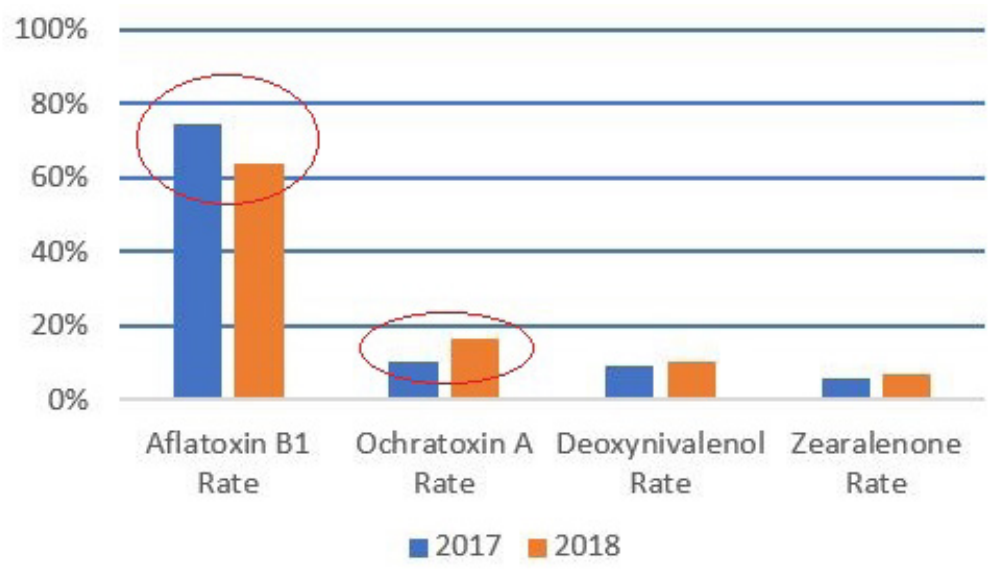

Figure 2. Variability of Mycotoxin Contamination in Dairy Cow Feed

Table 2. Mycotoxin Distribution in Feed by County

\begin{tabular}{|c|c|c|c|c|c|c|c|}
\hline Type of Feed & Period & County & AFB1 & ОTA & DON & ZEN & Aflatoxin $\Sigma$ \\
\hline \multirow{3}{*}{ Dairy Cow Feed } & \multirow{3}{*}{2017} & Călăraşi & $75.95 \%$ & $13.92 \%$ & $6.32 \%$ & $3.8 \%$ & - \\
\hline & & Giurgiu & $68.75 \%$ & - & $18.75 \%$ & $12.5 \%$ & - \\
\hline & & Teleorman & $85.71 \%$ & $14.29 \%$ & - & - & - \\
\hline \multirow{3}{*}{ Dairy Cow Feed } & \multirow{3}{*}{2018} & Călăraşi & $63.64 \%$ & $17.27 \%$ & $10 \%$ & $7.27 \%$ & $1.82 \%$ \\
\hline & & Giurgiu & $100 \%$ & - & - & - & - \\
\hline & & Teleorman & $50 \%$ & - & $50 \%$ & - & - \\
\hline \multirow{3}{*}{ Swine Feed } & \multirow{3}{*}{2017} & Călăraşi & $74.92 \%$ & $3.57 \%$ & $17.86 \%$ & $3.57 \%$ & - \\
\hline & & Giurgiu & $50 \%$ & - & $50 \%$ & - & - \\
\hline & & Teleorman & $60 \%$ & - & $20 \%$ & $20 \%$ & - \\
\hline
\end{tabular}


OTA contamination between in 2017 (13.92\%) and $2018(17.27 \%)$. OTA was detected in a few samples of swine feed from 2017 (3.57\%). In 2017 OTA was present in also in Teleorman (14.29\%). DON and ZEN were present in 2017 in feed for dairy cows and swine collected from Călăraşi $(6.32 \%$, and $3.8 \%$ respectively $17.86 \%$ and $3.57 \%$ ) and Giurgiu (18.75\% and $12.5 \%$ respectively $50 \%$ and $0 \%$ ). The following year, the same toxins were detected in dairy cow feed from Călăraşi $(10 \%$, respectively 7.27\%).

In 2017, AFB1 had a 100\% incidence in alfalfa hay and silage maize for dairy cows (Figure 3.). The second product affected was cereal maize (90\%), followed by grain cereals, cereals (wheat), grain maize, combined fodder (middlings), combined fodder, soy grist, rapeseed grist and sunflower grist. The highest level of contamination for AFB1 was $0.0033 \mathrm{ppm}$ in cereals (grain maize) collected from Călăraşi, for OTA 0.0006 ppm in combined fodder and middlings from the same county, for ZEN $<0.0001 \mathrm{ppm}$ in various types of feed from Călăraşi and Giurgiu and for DON 0.089 ppm in barley grains from Călărași.

In 2018, AFB1 had a 100\% incidence in grain cereal and sunflower grist for dairy cows

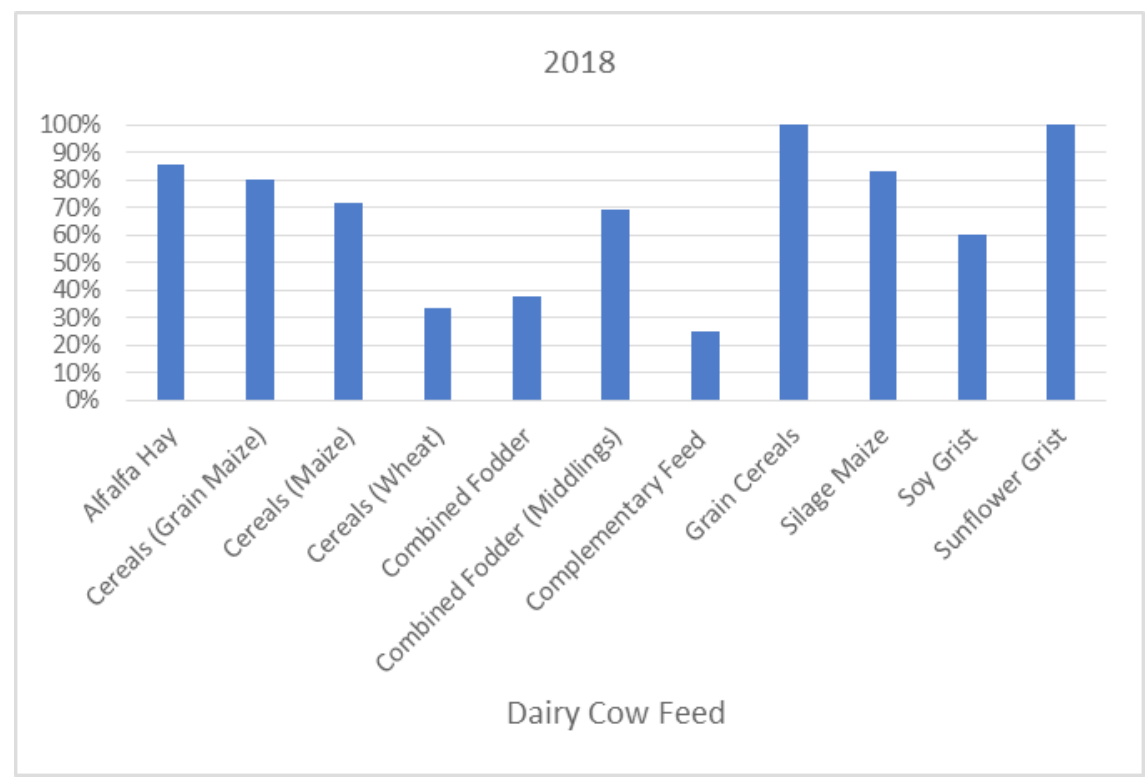

Fig 3. Comparative Contamination with AFB1 in Dairy Cow Feed

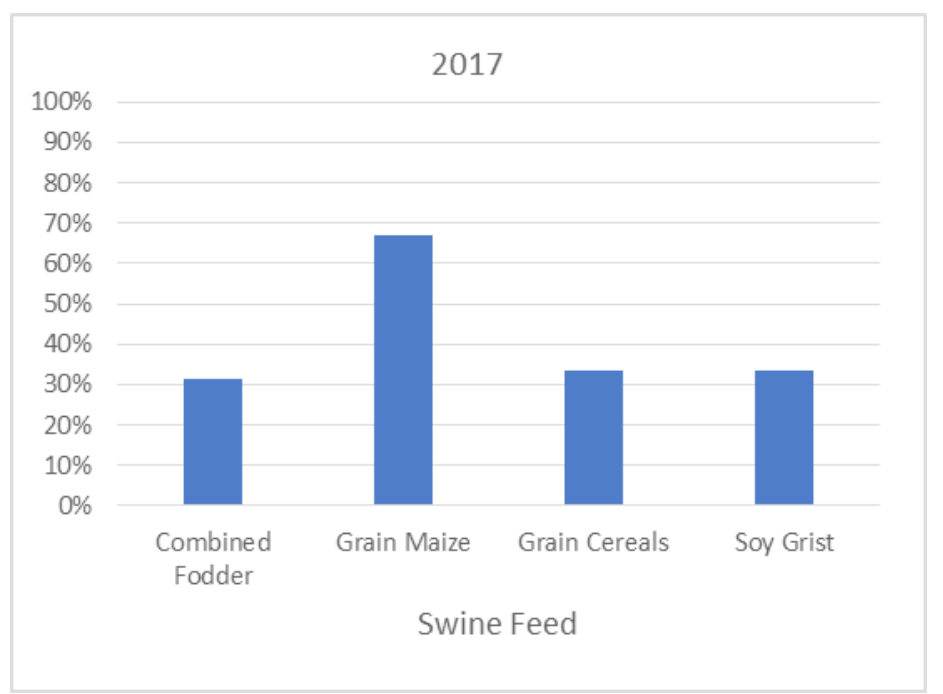

Figure 4. AFB1 Contamination Rate in Swine Feed from 2017 
(Figure 3.). The incidence exceeded 50\% in alfalfa hay, cereals (grain maize), silage maize and soy grist. However, the incidence of AFB1 dropped with $13.23 \%$ comparing to the previous year, while OTA, DON and ZEN increased. The highest incidence of DON (66.66\%) and OTA (>50\%) was recorded in cereals (wheat). The highest level of contamination for AFB1 was 0.016 ppm in cereals (maize), for OTA $0.0006 \mathrm{ppm}$ in cereals (barley) and complementary feed, for ZEN $0.021 \mathrm{ppm}$ in cereals (wheat) ppm and for DON $0.154 \mathrm{ppm}$ in combined fodder, all coming from Călăraşi County. Stanciu et al., 2019 associated DON and ZEA with wheat production from North Muntenia and linked their occurrence to the weather conditions.

In 2017, AFB1 was mainly found in grain maize for pigs. The other types of analyzed feed, such as combined fodder, grain cereal and soy grist had a similar incidence for AFB1 (Figure 4.). The highest level of contamination for AFB1 was $0.0007 \mathrm{ppm}$ in combined fodder and grain maize, for OTA $<0.0001 \mathrm{ppm}$ in combined fodder, for ZEN $<0.0002 \mathrm{ppm}$ in grain legumes, all coming from Călăraşi. The highest level of contamination for DON was $0.520 \mathrm{ppm}$ in combined fodder from Teleorman.

\section{Conclusions}

None of the samples exceeded the MRLs. However, residues of AFB1, OTA, DON and ZEN were quantifiable and therefore, concerns regarding the functionality of the quality management systems involved feedstuff production and storage conditions in the studied area exist. Due to its location (plain terrain), sudden climate changes are known to occur more often. The agro-climatic conditions could have most certainly contributed to the levels of mycotoxin contamination in the 3 counties (Călăraşi, Giurgiu and Teleorman) of SE Romania. The region should be continuously monitored especially nowadays when we are confronting global climate change. Special attention should be focused on the incidence of AFB1 and the level of contamination with DON in cereals for dairy cows and pigs (e.g. maize, barley, wheat), combined fodder, middlings and complementary fodder for dairy cows, and finally combined fodder and grain legumes for pigs.

Acknowledgments: This research did not receive any specific grant from funding agencies in the public, commercial, or not-for-profit sectors.

\section{References}

1. Alexa E, Dehelean CA, Poiana MA, Radulov I, Cimpean AM, Bordean DM, Tulcan C, Pop G (2013). The occurrence of mycotoxins in wheat from western Romania and histopathological impact as effect of feed intake, Chem Cent J., 7(1): 99.

2. Alshannaq A, Yu JH (2017). Occurrence, Toxicity, and Analysis of Major Mycotoxins in Food. Int J Environ Res Public Health, 14(6):632.

3. Barkai-Golan R, Paster N (2008). Mouldy fruits and vegetables as a source of mycotoxins: part 1, World Mycotoxin Journal 2008 1:2, 147-159.

4. Bryden WL (2012). Mycotoxin contamination of the feed supply chain: Implications for animal productivity and feed security, Animal Feed Science and Technology, 173(1-2):134-158.

5. Bui-Klimke TR, Wu F (2015). Ochratoxin A and human health risk: a review of the evidence, Critical reviews in food science and nutrition, 55(13), 1860-1869.

6. Avram M, Popa ME, Nicultita P, Belc N (2006). Mycotoxins in Cereal Products from Romania, In book: Case Studies in Food Safety and Environmental Health.

7. Changwa R, Abia W, Msagati T, Nyoni H, Ndleve K, Njobeh $P$ (2018). Multi-Mycotoxin Occurrence in Dairy Cattle Feeds from the Gauteng Province of South Africa: A Pilot Study Using UHPLC-QTOF-MS/MS, Toxins, 10(7): 294.

8. Fink-Gremmels J, Van der Merwe D (2019). Mycotoxins in the food chain: contamination of foods of animal origin, Chemical hazards in foods of animal origin, 241-261.

9. Gagiu V, Mateescu E, Armeanu I, Dobre A A, Smeu I, Cucu M E, Oprea O A, Iorga E, Belc N (2018). Post-Harvest Contamination with Mycotoxins in the Context of the Geographic and Agroclimatic Conditions in Romania, Toxins, 10, 533.

10. Gruber-Dorninger C, Jenkins T, Schatzmayr G (2018). Multi-mycotoxin screening of feed and feed raw materials from Africa, World Mycotoxin Journal, Special Issue: Mycotoxins in Africa.

11. Hamid AS, Tesfamariam IG, Zhang Y, Zhang ZG (2013). Aflatoxin B1-induced hepatocellular carcinoma in developing countries: Geographical distribution, mechanism of action and prevention, Oncology letters, 5(4), 1087-1092.

12. Hussein H, Brasel J M (2001). Toxicity, metabolism, and impact of mycotoxins on humans and animals, Toxicology, 167(2):101-34.

13. IARC. (1993). IARC Monographs on the evaluation of carcinogenic risks to humans: some naturally. Lyon: International Agency for Research on Cancer, 489-521.

14. Iheshiulor OOM, Esonu BO, Chuwuka OK, Omede AA, Okoli IC Ogbuewu IP (2010). Effects of Mycotoxins in Animal Nutrition: A Review, Asian Journal of Animal Sciences, 5(1):19-33.

15. Iqbal SZ, Jinap S, Pirouz AA, Ahmad Faizal AR (2015). Aflatoxin M1 in milk and dairy products, occurrence and recent challenges: A review, Trends in Food Science \& Technology 46: 110-119. 
16. Iqbal SZ, Selamat J, Ariño A (2016). Mycotoxins in Food and Food Products: Current Status, Chapter 6, In book: Food Safety; Basic Concepts, Recent Issues, and Future 5 Challenges, Edition: 1st Edition, Publisher: Springer Germany, Food Safety, 113-123.

17. Irakli MN, Skendi A, Papageorgiou MD (2017). HPLCDAD-FLD Method for Simultaneous Determination of Mycotoxins in Wheat Bran, Journal of Chromatographic Science, 55: (7) 690-696.

18. Kowalska K, Habrowska-Górczyńska DE, PiastowskaCiesielska AW (2016). Zearalenone as an endocrine disruptor in humans, Environ Toxicol Pharmacol, 48:141149.

19. Kumar P, Mahato DK, Kamle M, Mohanta TK, Kang S G (2017). Aflatoxins: A Global Concern for Food Safety, Human Health and Their Management, Frontiers in microbiology, 7, 2170.

20. Li X, Zhao L, Fan Y, Jia Y, Sun L, Ma S, Ji C, Ma Q, Zhang J (2014). Occurrence of mycotoxins in feed ingredients and complete feeds obtained from the Beijing region of China. J Anim Sci Biotechnol, 5(1):37.

21. Ma R, Zhang L, Liu M, Su Y T, Xie W M, Zhang N Y, Dai J F, Wang Y, Rajput S A, Qi D S., Karrow NA, Sun LH (2018). Individual and Combined Occurrence of Mycotoxins in Feed Ingredients and Complete Feeds in China. Toxins (Basel), 10(3):113.

22. Magnussen A, Parsi MA (2013). Aflatoxins, hepatocellular carcinoma and public health. World J Gastroenterol, 19(10):1508-12.

23. Marin S, Ramos AJ, Cano-Sancho G, Sanchis V (2013). Mycotoxins: occurrence, toxicology, and exposure assessment, Food Chem Toxicol., 60:218-37.
24. Metzler M, Pfeiffer E, Hildebrand AA (2015). Zearalenone and its metabolites as endocrine disrupting chemicals, World Mycotoxin Journal, 3 (4): 385-401.

25. Omotayo OP, Omotayo AO, Mwanza M, Babalola OO (2019). Prevalence of Mycotoxins and Their Consequences on Human Health, Toxicol. Res., 35(1):1-7.

26. Pinotti L, Ottoboni M, Giromini C, Dell'Orto V, Cheli F (2016). Mycotoxin Contamination in the EU Feed Supply Chain: A Focus on Cereal Byproducts, Toxins (Basel), 15;8(2):45.

27. Schatzmayr G, Streit E (2013). Global occurrence of mycotoxins in the food and feed chain: facts and figures. World Mycotoxin Journal, 6(3), 213-222.

28. Sobrova P, Adam V, Vasatkova A, Beklova M, Zeman L, Kizek $\mathrm{R}$ (2010). Deoxynivalenol and its toxicity, Interdisciplinary toxicology, 3(3), 94-99.

29. Stanciu O, Juan C, Berrada H, Miere D, Loghin F, Mañes J (2019). Study on Trichothecene and Zearalenone Presence in Romanian Wheat Relative to Weather Conditions. Toxins (Basel), 11(3):163.

30. Tabuc C, Taranu I, Calin L (2011). Survey of moulds and mycotoxin contamination of cereals in South-Eastern Romania in 2008-2010, Archiva Zootechnica 14:4, 25-38.

31. Tola M, Kebede B (2016). Occurrence, importance and control of mycotoxins: A review. Cogent Food \& Agriculture, 2(1).

32. Zain ME (2011). Impact of mycotoxins on humans and animals, Journal of Saudi Chemical Society, 15, (2):129144.

33. Becker-Algeri TA, Castagnaro D, de Bortoli K, de Souza C, Drunkler DA, Badiale-Furlong E (2016). Mycotoxins in Bovine Milk and Dairy Products: A Review, J Food Sci, 81(3): R544-52.

34. Zain ME (2011). Impact of mycotoxins on humans and animals, Journal of Saudi Chemical Society, 15, (2):129144. 